\title{
Sheet Bending Deformation in Production of Thin-Walled Pipes
}

\author{
Tatjana V. Brovman \\ Tver State Technical University, Tver, Russia \\ Email: brovman@mail.ru
}

Received 23 September 2014; revised 17 October 2014; accepted 11 November 2014

Copyright (C) 2014 by author and Scientific Research Publishing Inc.

This work is licensed under the Creative Commons Attribution International License (CC BY).

http://creativecommons.org/licenses/by/4.0/

(c) (i) Open Access

\begin{abstract}
Nowadays, thin-walled super-diameter pipes are produced by the method of plastic bending of sheets. After a sheet is bent into a pipe and its ends are welded, a pipe billet is subjected to expansion deformation. The technology of forming end areas of a sheet is developed and formulaes forming forces equations are deduced. Experimental investigations of deformation are undertaken.
\end{abstract}

\section{Keywords}

Plastic Deformation, Bending of Billets, Calculation of Forming Forces, Quality of Pipes

\section{Introduction}

Nowadays thin-walled pipes are made of metal sheets by the method of plastic bending in terms of the required diameter with the following welding of edges by a longitudinal seam [1] [2].

Sometimes two half-cylinder billets are bent with the following welding by two longitudinal seams.

Elastoplastic bending is used for production of high-strength steel pipes of super-diameter (1020 - $1420 \mathrm{~mm}$ and more), with the length being up to 18 metres and wall thickness to $40-55 \mathrm{~mm}$. Bending is produced by the "step-by-step forming" method, with the sheet being moved after every strain cycle.

Since dimensional accuracy of pipes thus produced is low, end areas of sheets are stamped, (pressed by two curved dies) [2]-[4].

The choice of technological modes, however, is hampered by the lack of formulas to calculate the required parameters of bending in view of residual deformations. Besides, there are no experimental data on the intensity of sheet deformation in dies.

In this paper we present theoretical dependence of bending deformation and residual deformation on the deformation forces and give the experimental results on the investigation of die forming forces in the end areas of 
sheets.

\section{Relation of Deflection of Billet to Be Formed and Value of Its Bending Flexure}

Figure 1 shows a diagram of bending the billet at the length 1 produced by a pressure roller (Figure 1(a)) or a punch (Figure 1(b)). When a sheet of width $b$ and thickness $\mathrm{h}$ is bent by force $P$, in most cases one can use the model of an ideal elastoplastic body with constant yield point $\sigma_{T}$ and modulus of elasticity $E$.

In this case two dimensionless parameters, as per [5], are inserted to the methods of calculation of elastoplastic bending

$$
m=\frac{P l}{4 \sigma_{T} b h^{2}}, n=\frac{\sigma_{T} l}{E h}
$$

where the first one characterizes a ratio between the force (and the maximum bending moment) and the limit plastic moment, while the second - a ratio of elastic and plastic properties of metal.

Figure 1(c) shows a bending moment diagram $M(x)$, where $x$ is a longwise coordinate of a billet. Maximum bending moment $0.25 \mathrm{Pl}$ acts in the middle of the billet length where force $P$ is applied. Maximum deflection in the cross section $x=0.5 \mathrm{l}$ is calculated by the standard method [3] [4]. It is equal to

$$
\frac{V_{m}}{a l}=\frac{0.024}{m^{2}}[0.96-(1+2 m) \sqrt{1-4 m}]
$$

If, for example, a metal sheet with yield point $\sigma_{T}=300 \mathrm{MH} / \mathrm{m}^{2}$, modulus of elasticity $E=2 \times 10^{5} \mathrm{MH} / \mathrm{m}^{2}$, length $l=1 \mathrm{~m}$ and thickness $h=4 \times 10^{-2} \mathrm{~m}$, then value $\frac{V_{m}}{a l}=0.2$ under the load defined by parameter $m=$ 0.2 .

At present value $a=\frac{300 \times 1}{2 \times 10^{5} \times 4 \times 10^{-2}}=3.75 \times 10^{-2}$ deflection at the midpoint of a billet is equal to

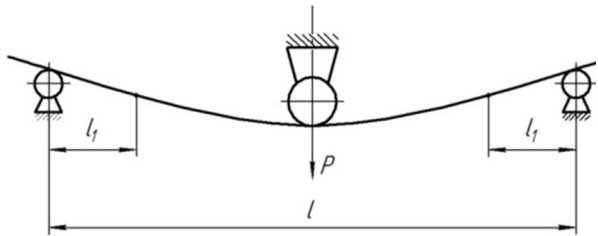

(a)

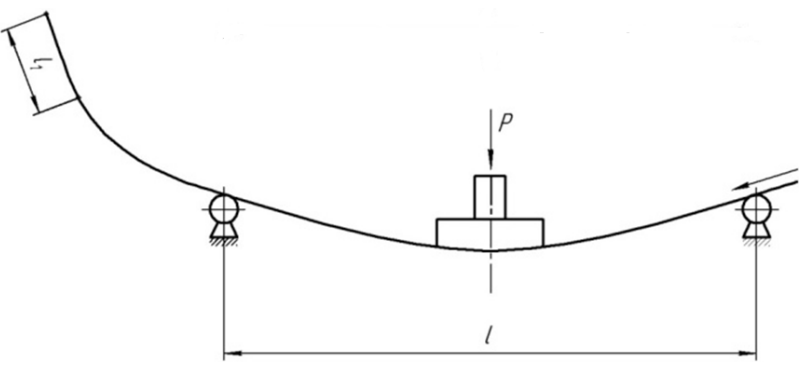

(b)

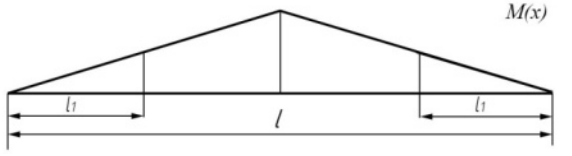

(c)

Figure 1. Bending deformation diagrams: (a) Bending by pressure of roller; (b) Serial step-by-step bending of a pipe; (c) Bending moment. 
$V_{m}=7.5 \times 10^{-3} \mathrm{~m}$

Formula (1) is may be used only in the range of $\frac{1}{6} \leq m \leq \frac{1}{4}$, if $m=\frac{1}{6}$, then $V_{m}=0.167$ al (but if $m<\frac{1}{6}$, linear dependence $\frac{V_{m}}{a l}=m$ is valid).

In the course of bending the value of maximum curvature is attained if $x=0.5 l$ (Figure 1).

$$
K_{m}=\frac{2 a}{l}\left(\frac{1}{\sqrt{3} \sqrt{1-4 m}}\right)
$$

However, after off-loading which occurs under elastic deformation, the residual curvature of a billet is equal to

$$
K_{0}=\frac{2 a}{l}\left(\frac{1}{\sqrt{3} \sqrt{1-4 m}}-6 m\right)
$$

If $a=3.75 \times 10^{-2}$ and $m=0.2$

$$
\begin{gathered}
K_{m}=\frac{2 \times 3.75 \times 10^{-2}}{1 \sqrt{3}} \frac{1}{\sqrt{0.2}}=9.7 \times 10^{-2} \mathrm{~m}^{-1}, \\
K_{0}=\frac{2 \times 3.75 \times 10^{-2}}{1}\left(\frac{1}{\sqrt{3 \times 0.2}}-1.2\right)=0.68 \times 10^{-2} \mathrm{~m}
\end{gathered}
$$

It is seen that value $K_{0}$ is much less than $K_{m}$. With increase of $m=0.24, K_{0}=1.45 m^{-1}$ i.e. the flexure increases 2.1 times (compared to the load when $m=0.2$ ).

If $m \leq \frac{1}{6}$, only elastic deformations take place. So if $m=\frac{1}{6}, K_{0}=0$ and the residual curvature is equal to zero (value $K_{m}=\frac{2 a}{l}$ when $m=\frac{1}{6}$ ). If bending moment tends to limiting value $m=\frac{1}{4}, K_{m} \rightarrow \infty$ and $K_{0} \rightarrow \infty$.

In the conditions of elastoplastic medium without hardening and $\sigma_{T}=$ const, plastic deformation billet at the surface of a stock in the middle of its length, and this area will expand with the increase of load. If $m=\frac{1}{4}$, plastic deformation (in the center of a billet) will cover the whole section and this means the loss of billet bearing capacity (for the material without hardening).

Function graph $\frac{V_{m}}{a l}$ from load parameter $m$ is given in Figure 2. It is seen that the rate of deflection increases when $m \rightarrow 0.25$.

However, near the ends of the sheets to be bent there are sections $l_{1}$ (Figure 1) where plastic deformation is not possible. Their length is:

$$
l_{1}=\frac{l}{12 m}
$$

Since a limiting value of non-dimensional load parameter $m=\frac{1}{4}$, minimum length $l_{1}=\frac{l}{3}$. This means that plastic bending deformation under the diagram of Figure 1 can be performed only along the length equal to one-third of the total billet length, i.e. the distance between supports.

According to the bending diagram of Figure 1(a), two-thirds of a billet length remains straight. According to the step-by-step bending diagram of Figure 1(b), a billet is gradually moved then brought to stop in order to be bent and it again keeps approaching as shown by the arrow. Each approach step should not be greater than value $\frac{l}{3}$, it is better to take it equal to $l$ (not exceeding $0.15-0.20$ ). The lower the value of a step motion, the higher 


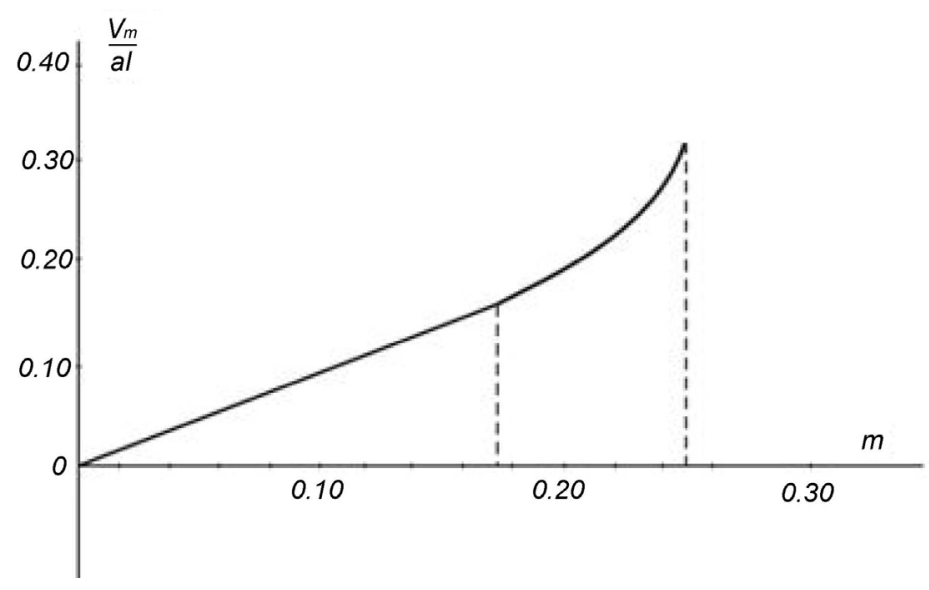

Figure 2. Function graph $\frac{V_{m}}{a l}$ from load parameter $m$.

the dimensional accuracy of a molded pipe (or a bent billet).

In this process, in contrast to a single-step bending (Figure 1(a)), the dimensional accuracy of a billet is higher, but segments of length $l_{1}$ remain still straight (Figure 1(b)) at the nose and butt ends of a billet.

This will make a billet or a pipe after bending deformation be configured as shown in Figure 3 .

It does not make much difference in manufacturing ring billets used in mechanical engineering, for example straps, especially if they are machined anyhow.

However, flat areas in manufacturing pipes greatly reduce their quality. As noted in [3], differences in diameter values (their nominal values 1000 - $1500 \mathrm{~mm}$ ) can reach $8-15 \mathrm{~mm}$, and these pipes are often unsuitable for pipelines.

Therefore, many large-diameter pipe manufacturers use the SMS MEER technology as per which end areas of sheets (edges) are bent by a flanging machine. After welding pipe billet is subjected to internal expanding by pressure of 12 wedges. First an arbor with wedges is got into the pipe, and then radial movement of wedges exerts pressure on the inner surface of pipe and increases its diameter, thus reducing flexure fluctuations. However, the pressure near $A$ and $B$ (Figure 3) can result in plastic deformation near weld zone C. Microcracks can appear in the zones under substantial tensile stress near pipe inner surface during expansion. The presence of residual stress is also important. There are some facts (see [3]) that most fractures of X70 steel pipes of $1420 \mathrm{~mm}$ diameter at gas pipelines occur on areas up to $200 \mathrm{~mm}$ from a longitudinal weld. It is clear that the pipes with two longitudinal welds do not have two flat areas, as shown in Figure 3, but four ones and so twice higher possibility of defect development when expanding.

That is why the quality of such pipes compared with single-weld ones is lower. Pipe stress-relief tempering at $250^{\circ} \mathrm{C}-300^{\circ} \mathrm{C}$ during two hours is sometimes recommended to prevent stress-corrosion [3].

However, tempering reduces residual stress but cannot help in cases of developing microcracks or delamination during pipe diameter expansion. In addition, such tempering leads to high energy consumption up to 1.8 2.0 MJ per a metric ton of pipes. In consideration of large pipe length (up to $10-12 \mathrm{~m}$ and more) the energy consumption will be two-three times higher due to losses.

Thus, it is highly desirable for end areas of billets to be compressed between dies as shown in Figure 4.

The above mentioned process is used in practice which is, however, difficult because of the lack of experimental data on the intensity of stress for deformation in forming sheet stock end areas.

\section{Force Determination in Stock End Area Die Forming}

The initial position of a stock end area is indicated by a dotted line in Figure 4. Firstly, a moving die contacts line $A$ (Figure 4), then bends the section which envelopes the surface of a counter die. Dies 1 and 2 come closer and deform stock 3 so that it forms the curvature $K=\frac{1}{R}$, constant along the die lengths. 


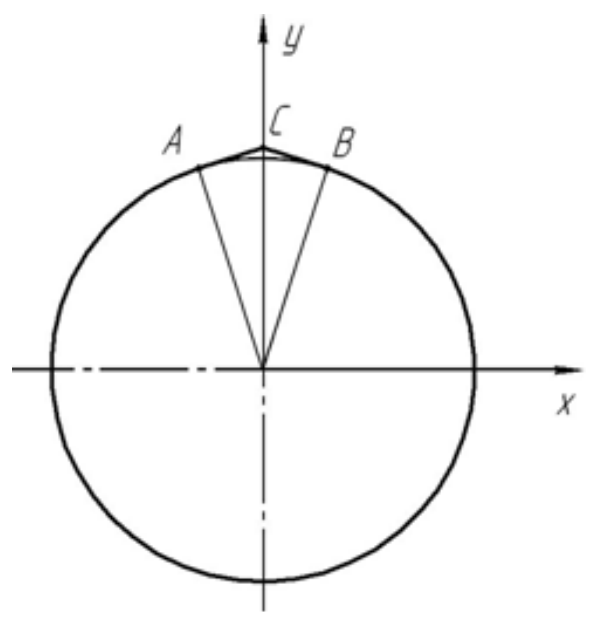

Figure 3. Diagram of flat sections in pipe forming.

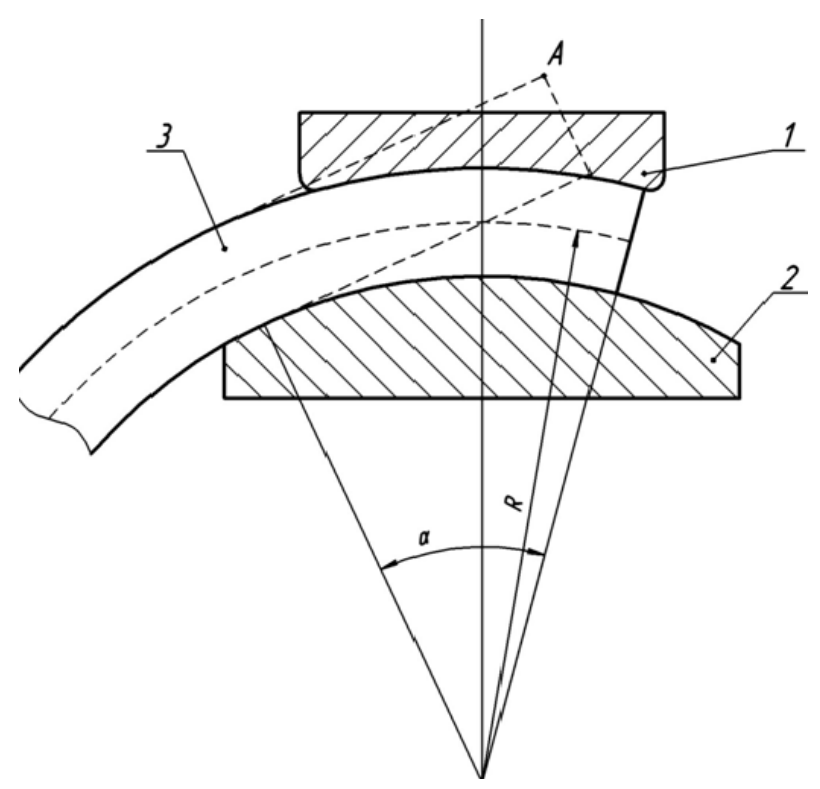

Figure 4. Deformation diagram of sheet end area in compressing between dies.

Provide the parameters determining the intensity of force, with their dimensions given in brackets: $R(\mathrm{~m}), h$ $(\mathrm{m}), \sigma_{T}\left(\mathrm{~N} / \mathrm{m}^{2}\right), b(\mathrm{~m}), l(\mathrm{~m}), P(\mathrm{~N})$, where $P$ is deformation force.

The parameters can be used to make four dimensionless parameters

$$
A_{1}=\frac{l}{R}, A_{2}=\frac{h}{l}, A_{3}=\frac{b}{R}, A_{4}=\frac{P}{\sigma_{T} b l} .
$$

According to $\pi$ theorem the relation of the indicated parameters must be in the form

$$
F\left(A_{1}, A_{2}, A_{3}, A_{4}\right)=0
$$

or, if it is solved relative to $A_{4}$, we can derive $A_{4}=f\left(A_{1}, A_{2}, A_{3}\right)$ or

$$
P=\sigma_{T} b l f\left(A_{1}, A_{2}, A_{3}\right)
$$

It should be accepted that the force is in proportion to the width of metal sheet so $f\left(A_{1}, A_{2}, A_{3}\right)$ does not depend on parameter $A_{3}$. Hence Equation (2) can be written as 


$$
P=\sigma_{T} b l f\left(\frac{h}{l}, \frac{l}{R}\right)
$$

To determine the upper limit of capacity and force values, a kinematically admissible velocity field was used (in polar coordinates)

$$
V_{r}=0, V_{\theta}=c \theta r(r-R), V_{z}=-c z(r-R),
$$

where $r, \theta, z$ are coordinates, $c$ is a constant, $R$ is a stock mean radius (its neutral axis). The components of deformation velocity tensor are determined by conventional equations, see [4].

$\varepsilon_{r}=0, \varepsilon_{\theta}=c(r-R), \varepsilon_{z}=-c(r-R)$, and form change capacity

$$
N=\int_{-0.5 b}^{+0.5 b} \mathrm{~d} z \int_{-0.5 \alpha}^{+0.5 \alpha} \mathrm{d} \theta \int_{R-0.5 h}^{R+0.5 h} \frac{\sigma_{T}}{\sqrt{3}} H r \mathrm{~d} r
$$

where the second invariant of deformation velocity tensor is

$$
H=\sqrt{\frac{2}{3}\left[\left(\varepsilon_{r}-\varepsilon_{\theta}\right)^{2}+\left(\varepsilon_{\theta}-\varepsilon_{z}\right)^{2}+\left(\varepsilon_{z}-\varepsilon_{r}\right)^{2}\right]+\gamma_{r z}^{2}+\gamma_{r \theta}^{2}+\gamma_{\theta z}^{2}},
$$

where $\gamma_{r z}, \gamma_{r \theta}, \gamma_{\theta z}$ are the components corresponding to shear strain.

Numerical calculations, according to (6), show the possibility of the approximate description of function $N$ in the form of

$$
N=\frac{2}{3 \sqrt{3}} \sigma_{T} b h^{2} \omega
$$

where $\omega=\frac{\alpha}{\tau_{0}}$ is the mean angular velocity of bending an end area and $\tau_{0}$ is the time of forming a sheet billet end area.

Hence we derive the equation

$$
P=\frac{4 \sigma_{T} b h^{2}}{3 \sqrt{3} l}
$$

which matches relation (5) with $f\left(\frac{h}{l}, \frac{l}{R}\right)=\frac{4}{3 \sqrt{3}}\left(\frac{h}{l}\right)^{2}$.

To verify the given equations experimental investigations were conducted. They measure the forces deformation of billet ends was made on the press with $1 \mathrm{MN}$ force for steel sheets, with yield strength being $260 \mathrm{MN} / \mathrm{m}^{2}$, the width of sheets being $b=0.6 \mathrm{~m}$ and thickness $-h=5 \times 10^{-3} \mathrm{~m}, 10 \times 10^{-3} \mathrm{~m}$ and $20 \times 10^{-3} \mathrm{~m}$. In addition parameters $l$ and $R$ in ranges $l=0.2-0.9 \mathrm{~m}$ and $R=0.2-1.1 \mathrm{~m}$ were changed in the tests. The part of experimental data for sheets of $0.6 \mathrm{~m}$ width and the three thicknesses is given in Table 1 with $l=0.9 \mathrm{~m}, l=0.4 \mathrm{~m}$ and $l=$ $0.2 \mathrm{~m}$.

Table 2 shows the data on the results of the force measurement with $b=0.6 \mathrm{~m}, l=0.4 \mathrm{~m}$ and $h=4 \times 10^{-2} \mathrm{~m}$ for the same carbon steel with $\sigma_{T}=260 \mathrm{MN} / \mathrm{m}^{2}$. The average value of the force is: $409.93 \mathrm{kN}$, the dispersion being $21.3(\mathrm{kN})^{2}$.

Thus a standard deviation is $4.62 \mathrm{kN}$ and, following "the rule of three standard deviation", can be surely assumed (with high probability of 0.997 ) that the intensity of force is in the range of $409.93 \pm 3 \times 4.62$ or 396 $424 \mathrm{kN}$. The range of $28 \mathrm{kN}$ or $0.066 P_{m}$ matches the possible oscillations of formation intensities of force. Deviations of (7) type equations up to $20 \%-25 \%$ are to be taken into consideration in choosing and designing the equipment for forming pipe end areas.

General Equations of (4) and (5) form based on the dimensional theory should be specified with further experimental studies.

If Equation (3) takes the function

$$
f\left(\frac{h}{l}, \frac{l}{R}\right)=0.77 \frac{h^{2}}{l^{2}},
$$


Table 1. Values of force in bending.

\begin{tabular}{|c|c|c|c|c|c|c|c|c|c|}
\hline \multicolumn{10}{|c|}{$l=0.9 \mathrm{~m}$} \\
\hline Sheet thickness, mm & \multicolumn{3}{|c|}{$h=5 \mathrm{~mm}$} & \multicolumn{3}{|c|}{$h=10 \mathrm{~mm}$} & \multicolumn{3}{|c|}{$h=20 \mathrm{~mm}$} \\
\hline No. of measurement & 1 & 2 & 3 & 1 & 2 & 3 & 1 & 2 & 3 \\
\hline Force $P, \mathrm{kN}$ & 3.30 & 3.15 & 3.08 & 13.1 & 12.9 & 13.4 & 49.5 & 52.1 & 48.7 \\
\hline \multicolumn{10}{|c|}{$l=0.4 \mathrm{~m}$} \\
\hline Sheet thickness, mm & \multicolumn{3}{|c|}{$h=5 \mathrm{~mm}$} & \multicolumn{3}{|c|}{$h=10 \mathrm{~mm}$} & \multicolumn{3}{|c|}{$h=20 \mathrm{~mm}$} \\
\hline No. of measurement & 1 & 2 & 3 & 1 & 2 & 3 & 1 & 2 & 3 \\
\hline Force $P, \mathrm{kN}$ & 7.08 & 7.21 & 7.18 & 29.8 & 30.1 & 29.4 & 110.1 & 117.7 & 108.3 \\
\hline \multicolumn{10}{|c|}{$l=0.2 \mathrm{~m}$} \\
\hline Sheet thickness, mm & \multicolumn{3}{|c|}{$h=5 \mathrm{~mm}$} & \multicolumn{3}{|c|}{$h=10 \mathrm{~mm}$} & \multicolumn{3}{|c|}{$h=20 \mathrm{~mm}$} \\
\hline No. of measurement & 1 & 2 & 3 & 1 & 2 & 3 & 1 & 2 & 3 \\
\hline Force $P, \mathrm{kN}$ & 14.8 & 13.9 & 13.1 & 59.8 & 58.3 & 60.1 & 235.2 & 237.4 & 229.9 \\
\hline
\end{tabular}

Stock End Areas, (with $b=0.6 \mathrm{~m} ; \sigma_{T}=260 \mathrm{MN} / \mathrm{m}^{2} ; R=1 \mathrm{~m}$ ).

Table 2. Values of Force in forming sheet end areas ( $\left.b=0.6 \mathrm{~m} ; \sigma_{T}=260 \mathrm{MN} / \mathrm{m}^{2} ; l=0.4 \mathrm{~m} ; h=4 \times 10^{-2} \mathrm{~m}\right)$.

\begin{tabular}{cccccc}
\hline No. of measurement & Force $P, \mathrm{kN}$ & No. of measurement & Force $P, \mathrm{kN}$ & No. of measurement & Force $P, \mathrm{kN}$ \\
\hline 1 & 410.2 & 8 & 417.7 & 15 & 412.8 \\
2 & 405.0 & 9 & 418.1 & 16 & 401.8 \\
3 & 409.2 & 10 & 415.1 & 17 & 414.3 \\
4 & 403.8 & 11 & 412.6 & 18 & 408.8 \\
5 & 408.4 & 12 & 416.2 & 19 & 410.5 \\
6 & 404.1 & 13 & 414.8 & 20 & 403.2 \\
7 & 406.2 & 14 & 411.5 & 21 & 409.2 \\
\hline
\end{tabular}

we will derive Equation (7) according to which function $f$ only depends on one dimensionless parameter $\frac{h}{l}$.

But with small values of $\frac{l}{R}$ the parameter also has influence. With $\frac{l}{R}<0.4$ the following equation can be used

$$
f\left(\frac{h}{l}, \frac{l}{R}\right)=0.70 \frac{h^{2}}{l^{2}}+10^{-5} \frac{R^{2}}{l^{2}}
$$

For example, with $\frac{h}{l}=0.05 ; \frac{R}{l}=5 ; l=0.2 \mathrm{~m}$

$$
f\left(\frac{h}{l}, \frac{l}{R}\right)=0.70 \times 0.25 \times 10^{-2}+0.025 \times 10^{-2}=2 \times 10^{-3}
$$

and force $P=260 \times 0.6 \times 0.2 \times 2 \times 10^{-3}=62.4 \mathrm{kN}$.

With the increase of $\frac{l}{R}$ from 0.2 to 0.4 with the same value of $\frac{h}{l}=5 \times 10^{-2}$ the second member decreases to the magnitude not exceeding $5 \%$ of force. Hence, in forming pipes one should not leave too short $\left(\frac{l}{R}<0.3-0.4\right)$ flat areas of sections because they are more difficult to be bended in order to get the necessary flexure.

It is also to be taken into consideration that the bending force calculations based on conventional equations of the theory of plasticity can be used for bending the billet which is stationary during bending. (Billet can move between individual cycles of bending deformation but it is stationary in bending). If billet moves during plastic bending deformation, as it usually happens on rollers units, its movement changes a deformation process significantly. As [5] showed, in this case, even with the symmetric force, in Figure 1 the strain symmetry is distorted 
due to discharge in the zone of bending moment decrease so different equations should be used for calculating deflections at these zones.

\section{Conclusions}

1) The elastoplastic deformation of bending leaves flat areas in billets. It should be deformed to provide the constancy of the curvature along the pipe section. Thus, the formation of sheet end areas is necessary.

2) In bending the billet flat areas to get the necessary flexure (diameter), the choice of step-by-step forming press forces should be subjected to experimental data results and it is desirable to take parameter $\frac{l}{R}$ not less than 0.4 .

\section{References}

[1] Rymov, V.A., Polykhin, P.I. and Potapov, I.N. (1983) Improvement of Welded Pipe Production. Metallurgiya, Moscow, 307 p.

[2] Barabantsev, G.Ye., Tyulyapin, A.N., Kolobov, A.V. and Yusupov, V.S. (2005) Improvement of Electric-Welded Straight-Line-Seam Pipe Production Technology. Rolled Metal Production, 12, 21-23.

[3] Shinkin, V.N. (2013) Strength of Materials for Metallurgists. Textbook for Higher Schools, DomMISiS Publishing House, Moscow, 655 p.

[4] Hill, R. (1950) Mathematical Theory of Plasticity. Clarendon Press, Oxford, 407 p.

[5] Brovman, M.Ya. (1982) About Elastoplastic Bending of Beams in Movement. USSR Academy of Sciences, Mechanics of Solid Body, 3, 155-160. 
Scientific Research Publishing (SCIRP) is one of the largest Open Access journal publishers. It is currently publishing more than 200 open access, online, peer-reviewed journals covering a wide range of academic disciplines. SCIRP serves the worldwide academic communities and contributes to the progress and application of science with its publication.

Other selected journals from SCIRP are listed as below. Submit your manuscript to us via either submit@scirp.org or Online Submission Portal.
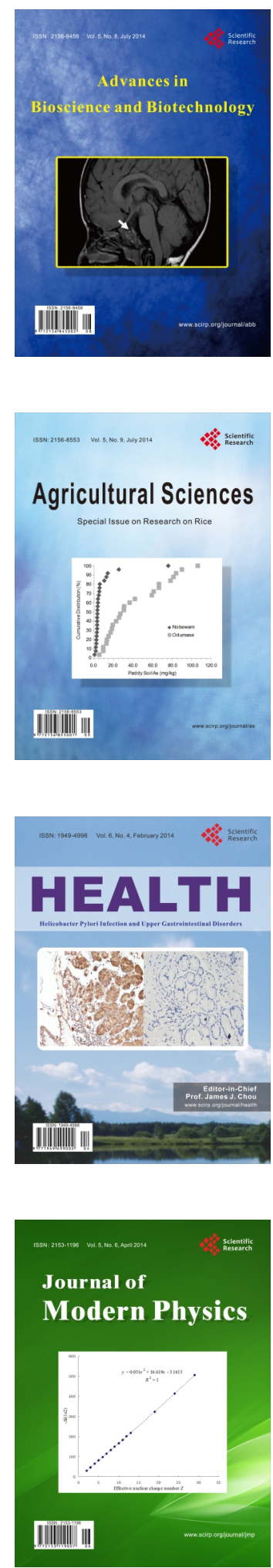
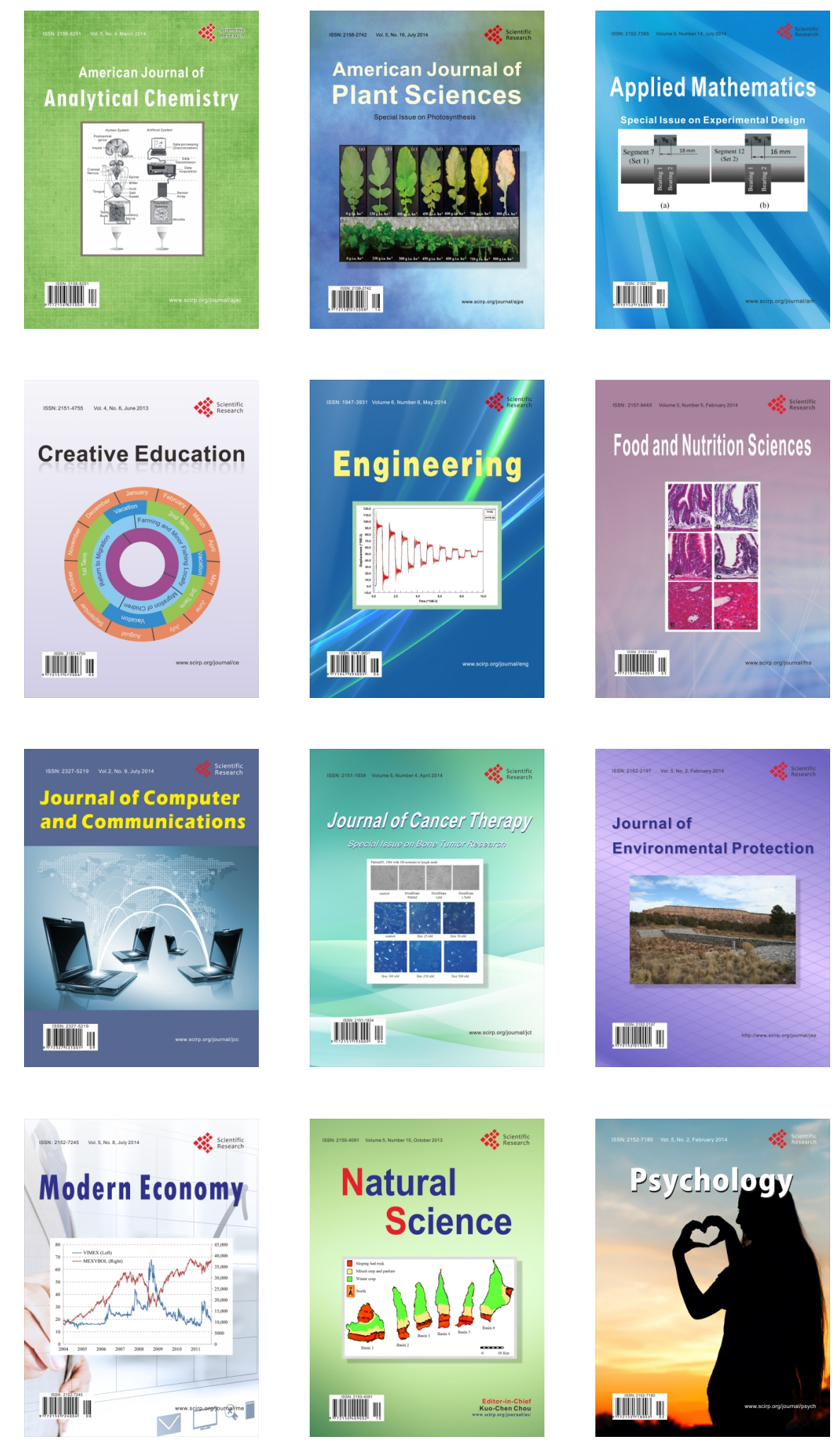